\title{
Can machines think? The controversy that led to the Turing test, 1946-1950
}

\author{
Bernardo Gonçalves ${ }^{1}$
}

\begin{abstract}
Turing's much debated test has turned 70 and is still fairly controversial. His 1950 paper is seen as a complex and multi-layered text and key questions remain largely unanswered. Why did Turing choose learning from experience as best approach to achieve machine intelligence? Why did he spend several years working with chess-playing as a task to illustrate and test for machine intelligence only to trade it off for conversational question-answering later in 1950? Why did Turing refer to gender imitation in a test for machine intelligence? In this article I shall address these questions directly by unveiling social, historical and epistemological roots of the so-called Turing test. I will draw attention to a historical fact that has been scarcely observed in the secondary literature so far, namely, that Turing's 1950 test came out of a controversy over the cognitive capabilities of digital computers, most notably with physicist and computer pioneer Douglas Hartree, chemist and philosopher Michael Polanyi, and neurosurgeon Geoffrey Jefferson. Seen from its historical context, Turing's 1950 paper can be understood as essentially a reply to a series of challenges posed to him by these thinkers against his view that machines can think.
\end{abstract}

Keywords: Alan Turing, Can machines think?, The imitation game, The Turing test, Mind-machine controversy, History of artificial intelligence.

Robin Gandy (1919-1995) was one of Turing's best friends and his only doctorate student. He received Turing's mathematical books and papers when Turing died in 1954, and took over from Max Newman in 1963 the task of editing the papers for publication. ${ }^{1}$ Regarding Turing's purpose in writing his 1950 paper and sending it for publication, Gandy offered a testimony previously brought forth by Jack Copeland which has not yet been commented about: ${ }^{2}$

It was intended not so much as a penetrating contribution to philosophy but as propaganda. Turing thought the time had come for philosophers and mathematicians and scientists to take seriously the fact that computers were not merely calculating engines but were capable of behaviour which must be accounted as intelligent; he sought to persuade people that this was so. He wrote this paper unlike his mathematical papers quickly and with enjoyment. I can remember him reading aloud to me some of the passages always with a smile, sometimes with a giggle. ${ }^{3}$

I shall refer to this as Gandy's anecdote on the purpose of the Turing test. It think it is intriguing, for one thing, because it diverges from the widely shared view of Turing's paper as the proposal of a decisive experiment for machine intelligence. But more than that, it suggests that Turing was engaged in a dialogue with 'philosophers and mathematicians and scientists' on the capabilities of digital computers. Now, what debate was this? Who were these interlocutors that Turing sought to persuade? While 'the Turing test' is widely known in philosophy, there is a gap of scholarly studies on its history. I shall gather a mass of available sources such as Gandy's anecdote that, although mostly known to Turing scholars, have not yet been tied together and fully appreciated for the sake of the interpretation of Turing's 1950 proposal.

1 University of São Paulo, Polytechnic School and Faculty of Philosophy, Languages and Human Sciences. Correspondence: begoncalves@usp.br. ORCID: 0000-0003-2794-8478 


\section{The purpose of the Turing test in the secondary literature so far}

Seventy years have passed since Turing's famous 1950 proposal of an imitation game or test for machine intelligence, ${ }^{4}$ and its available interpretations are still conflicting. At a first level of discussion, interpreters disagree on whether or not Turing proposed a definite experiment to decide for machine intelligence. On the one side, philosophers such as Daniel Dennett, James Moor and Jack Copeland all provided support for viewing Turing's test as such experiment. ${ }^{5}$ Dennett wrote that 'the Turing test, conceived as he conceived it, is (as he thought) plenty strong enough as a test of thinking;' and added 'I defy anyone to improve upon it'. ${ }^{6}$ This class of interpreters have found in Turing's 1950 paper an epic test for machines seen as a species as opposed to the human species and in neglect of any gender test whatsoever. They did not acknowledge the presence of the gendered machine-imitates-woman and machine-imitates-man variants of the imitation game. ${ }^{7}$ Rather, they suggested to read 'man' in Turing's second variant as masculine generics. They argued that by considering all primary sources and not only Turing's 1950 text, one ought to concede that Turing must have proposed not a gender, but a species test. (My contention is that Turing did propose gender learning and imitation as one of his various historical tests for machine intelligence.) And they insisted that the construed machine-imitates-human test stands as the best experiment to decide whether or not machines have already achieved humanlevel intelligence. On the other side, scientists such as Patrick Hayes and Kenneth Ford, and Drew McDermott, although less certain about what Turing tried to do in his paper, tried to take his 1950 proposal of a definite experiment for machine intelligence seriously and yet found no scientific substance in it. ${ }^{8}$ Also based on the working assumption that Turing would have proposed a decisive experiment for machine intelligence, this class of readers complained about the quality of Turing's experiment description and design, be it for a gender or for a species test. McDermott wrote that '[c]onsidering the importance Turing's Imitation Game has assumed in the philosophy-of-mind literature of the last fifty years, it is a pity he was not clearer about what the game was exactly.'

Furthermore there are those who suggested a deflationary view of Turing's 1950 proposal, if not rejected altogether that Turing's test addresses an empirical question. Blay Whitby acknowledged the role played by Turing's 1950 proposal in the early 1950's to inspire or drive research. But he claimed that soon later it became a distraction, for Turing's test rather measures the human reaction to a performative machine and this is not a problem in artificial intelligence research. ${ }^{9}$ Marvin Minsky said that 'the Turing test is a joke, sort of'; he considered that Turing suggested his test 'as one way to evaluate a machine but he had never intended it as the way to decide whether a machine was really intelligent'. ${ }^{10}$ Noam Chomsky wrote that '“can machines think?" is not a question of fact' but one of language, and that Turing himself observed that the question is 'too meaningless to deserve discussion'. ${ }^{11}$ These all are different representative classes of interpretation of Turing's 1950 proposal.

There is an encyclopedic account of Turing's test construed as a concept in analytic philosophy. ${ }^{12} \mathrm{~A}$ comprehensive survey on the so-called 'Turing test' in the philosophy of mind and in artificial intelligence research and was given by Saygin et al. in 2000. ${ }^{13}$ They are focused on the secondary literature, and not in historiographies of Turing's 1950 proposal.

Also in face of the sheer heterogeneity in the secondary literature on the Turing test, one may note that there is still much room in Turing scholarship for the historical study of Turing's 1950 proposal.

\section{Core events of 1949, the crucial year}

In June, computer pioneer, distinguished physicist and then University of Cambridge Professor Douglas Hartree published his Calculating instruments and machines. ${ }^{14}$ Described in detail in the book, the new electronic computing machines could do a lot and yet should be seen as nothing but calculation engines. Also in June, distinguished neurosurgeon and then University of Manchester Professor 
Geoffrey Jefferson had given his Lister Oration in London on 9 June 1949 along the same lines and pushed it further with strong demands to accept that 'machine equals brain'. ${ }^{15}$ Jefferson's memorial was covered by The Times. ${ }^{16}$ Asked by the reporter for a reply, Turing rebutted to Jefferson sharply, in wit. ${ }^{17}$ This indirect exchange with Jefferson, however, would only make an actual impact on Turing's views from October to December 1949 after two editions of a seminar, 'Mind and computing machine', in the Department of Philosophy of their university. ${ }^{18}$ These seminars were co-chaired by distinguished chemist and University of Manchester Professor of Social Studies Michael Polanyi, who also engaged in the mind-machine controversy with Turing. These three conservative thinkers, then all endowed with fellowships of the Royal Society and university professorships more prestigious than Turing's, who was then Reader at the University of Manchester's Department of Mathematics, tried to establish boundaries to Turing's views on machine intelligence. From June to December 1949 their challenges would resonate in Turing's thought and must have led to his famous 1950 paper, as we shall see. While these events are mostly known to Turing scholars, to the best of my knowledge they are yet to receive proper attention towards an interpretation of Turing's 1950 proposal of an imitation test for machine intelligence that is grounded in its history.

\section{The mind-machine controversy in England, 1946-1950}

Turing's dialogue with Hartree is observable, if for nothing else, through direct citations from 1950 to 1951 which addressed the possibility of learning machines. ${ }^{19}$ In spite of that, to my knowledge the influence of Hartree's opposition on Turing has barely been noted so far. Andrew Hodges offered an account of Turing's test and pointed to the Turing-Polanyi connection, writing that Polanyi 'encouraged [Turing] to publish his views'. ${ }^{20}$ In the most comprehensive biography on Turing, Hodges provided several valuable primary and secondary sources. ${ }^{21}$ And yet he often struggles with Turing's text in favor of, in my view, his own essayistic drives. For instance, he wrote that Turing's 'sexual guessing game' was 'in fact a red herring, and one of the few passages of the paper that was not expressed with perfect lucidity'. ${ }^{22}$ Jonathan Swinton's biography provided plenty of new valuable sources. ${ }^{23}$ Regarding Turing's test, Swinton emphasized the Turing-Jefferson connection. He pointed that 'it was Jefferson's obtuseness that provoked Turing into developing this vivid image [the Turing test]'. ${ }^{24}$ Swinton did not comment on why he thought so. Turing scholar Diane Proudfoot contributed an interpretation of Turing's 1950 proposal centered on a specific aspect of Turing's concept of machine intelligence, ${ }^{25}$ namely, Turing's 1948 observation that 'the idea of "intelligence" is itself emotional'. ${ }^{26}$ More broadly, Proudfoot concurs with Copeland's defense of the test as a decisive experiment for artificial intelligence. ${ }^{27}$ I shall also refer later to Darren Abramson's location of material evidence that Turing read and annotated Jefferson's 1949 citations of René Descartes. ${ }^{28}$ My contention, in any case, is that there is a need to connect specific findings such as this to the whole towards an overarching interpretation of Turing's 1950 test that is historically grounded and accomodates for the tensions in existing interpretations. This gap in the secondary literature can be illustrated by the general obliviousness on Gandy's anecdote but also by key exegetical and historical questions which still appear to be largely unanswered:

- Why did Turing choose learning from experience as best approach to achieve machine intelligence? In what context did he make this decision? Can we trace its intellectual history?

- If Turing was decided about conversational performance as the best intellectual task to illustrate, develop and test machine intelligence, why did he work for several years ever since his wartime service in 1941 up to his 1950 paper with chess-playing as such task, having even reconsidered it at the end of his 1950 paper?

- If Turing really proposed in 1950 a species test for machine intelligence in neglect of a gender test, 
why did he refer to gender imitation so vigorously in the same source?

Throughout my exposition of the key historical events in the year of 1949 coming next, in this article I shall develop relatively succinct answers for these questions. (An extended account can be found elsewhere. ${ }^{29}$ ) I suggest that Turing's 1950 proposal can be best understood against the background of the mind-machine controversy in England, 1946-1950, notably with Hartree, Polanyi and Jefferson. Altogether, this is the debate that led Turing to propose his famous imitation game or test for machine intelligence and gives intelligibility to it, including providing explanation for Robin Gandy's anecdote.

\section{Turing provoked by Douglas Hartree}

Douglas Hartree (1897-1958), F.R.S. since 1932, ${ }^{30}$ Plummer Professor of Mathematical Physics and member of the Cavendish Laboratory at the University of Cambridge since October 1946, had given his 'short series of lectures' in the early fall of 1948 at the University of Illinois. His related Calculating instruments and machines came out in about June $1949 .{ }^{31}$ In the preface, ${ }^{32}$ Hartree had cited the Manchester 'Baby' computer which had recently been 'put into operation.' (Earlier, in February 1946 Hartree had been a key figure for Newman's Computing Laboratory in Manchester to be granted funding from the Royal Society. ${ }^{33}$ ) And he kept pushing his public criticism on the term 'electronic brain', as he had been doing ever since his note on The Times in early November of 1946. It was after Hartree's 1949 book that Turing cited and discussed 'Lady Lovelace's objection', or 'Lady Lovelace's dictum'. ${ }^{34}$ Hartree thus drew attention to Lady Lovelace's views:

Some of her comments sound remarkably modern. One is very appropriate to a discussion there was in England which arose from a tendency, even in the more responsible press, to use the term "electronic brain" for equipment such as electronic calculating machines, automatic pilots for aircraft, etc. I considered it necessary to protest against this usage [Hartree, D. R. The Times (London), Nov. 7, 1946.], as the term would suggest to the layman that equipment of this kind could "think for itself," whereas this is just what it cannot do; all the thinking has to be done beforehand by the designer and by the operator who provides the operating instructions for the particular problem; all the machine can do is to follow these instructions exactly, and this is true even though they involve the faculty of "judgment." I found afterwards that over a hundred years ago Lady Lovelace had put the point firmly and concisely (C, p. 44): "The Analytical Engine has no pretensions whatever to originate anything. It can do whatever we know how to order it to perform" (her italics). ${ }^{35}$

Hartree further resumed it in a way that conceded a window for research on machine learning:

This does not imply that it may not be possible to construct electronic equipment which will "think for itself," or in which, in biological terms, one could set up a conditioned reflex, which would serve as a basis for "learning." Whether this is possible in principle or not is a stimulating and exciting question suggested by some of these recent developments [...]. But it did not seem that the machines constructed or projected at the time had this property. ${ }^{36}$

This passage would be quoted and discussed by Turing at length in $1950 .{ }^{37}$ Turing was decided to pursue machine learning beyond 'reflexes' and 'the action of the lower centres' of the brain at least since his $c$. November 1946 letter to Ross Ashby. ${ }^{38}$ In fact, as we will now see, Hartree was himself as of 1949 writing in reply to Turing.

Back in November 1946, Hartree had been interviewed alongside Turing about the machine (or 'brain') under construction at the National Physical Laboratory near London, the so-called Automatic Computing Engine (ACE). After the Second World War, Turing was hired to lead the design of the $\mathrm{ACE}$ as an implementation of his 1936 concept of universal machine, ${ }^{39}$ while Hartree had been 
collaborating with Maurice Wilkes on the EDSAC machine at the University of Cambridge. ${ }^{40}$ On 7 November The Daily Telegraph reported an account based on their interviews but whose headline centered on Hartree's views. ${ }^{41}$ Hartree is reported to have said: '[t]he implications of the machine are so vast that we cannot conceive how they will affect our civilisation.' But Hartree meant practical applications of scientific computing. Turing would have gone his own way: 'Dr Turing, who conceived the idea of [ACE], said that he foresaw the time, possibly in 30 years, when it would be as easy to ask the machine a question as to ask a man.' The contrast between Hartree's view and Turing's view was marked. Hartree has also been reported to have said in that 1946 interview, in line with his future citations of Lady Lovelace, that 'the machine would always require a great deal of thought on the part of the operator.' And he denied 'any notion that Ace could ever be a complete substitute for the human brain.' This was postwar Britain, and Hartree saw a connection between authoritarian regimes and Turing's projections for the machine. He added: '[t]he fashion which sprung up in the last 20 years to decry human reason is a path which leads straight to Nazism.' This was in spite of the fact that, as known, Turing served Britain in the war and helped to defeat Nazism by using computing machines.

Turing did not seem to have paid attention to Hartree's play of the Nazi card. But he must have felt compelled to respond to what was in essence, say, the Lovelace-Hartree thesis, for soon after their early November 1946 interviews, in the occasion of his February 1947 lecture on the ACE to the London Mathematical Society, ${ }^{42}$ he had already defined what would be his line of response. He accepted a premise of the thesis and questioned its conclusion:

It has been said that computing machines can only carry out the processes that they are instructed to do. This is certainly true in the sense that if they do something other than what they were instructed then they have just made some mistake. It is also true that the intention in constructing these machines in the first instance is to treat them as slaves, giving them only jobs which have been thought out in detail, jobs such that the user of the machine fully understands what in principle is going on all the time. Up till the present machines have only been used in this way. But is it necessary that they should always be used in such a manner? ${ }^{43}$

Turing seems to have observed that the objection raised by the Lovelace-Hartree thesis was strong and could only be met if machines were made to learn for themselves by experience, with no need to redesign. He said: '[w] hat we want is a machine that can learn from experience.' And completed: '[t]he possibility of letting the machine alter its own instructions provides the mechanism for this'. ${ }^{44}$ So, when Hartree wrote the above passage in 1949 denying that 'the machines constructed or projected at the time had this property' (of learning to think for themselves), he was already responding to Turing's February 1947 comment and perhaps also to Norbert Wiener's Cybernetics that was published soon later in October 1948. ${ }^{45}$ Wiener reported to have met Turing in the spring of 1947. Among other generous mentions of Turing, Wiener referred to Turing's results from his 1936 paper to conclude that 'the logic of the machine resembles human logic, and, following Turing, we may employ it to throw light on human logic'. ${ }^{46}$ From that passage, Wiener immediately proceeded to answer positively to the possibility of the machine to have even 'a more eminently human characteristic,' namely, 'the ability to learn.' Wiener made it public thereby that he shared Turing's non-obvious view that machines could be made to learn for themselves. Indeed, Wiener's Cybernetics did not pass unnoticed in Britain as we shall also see shortly by looking at Jefferson's participation in the mind-machine controversy.

Turing's iconic section on 'learning machines' is a high point of his 1950 paper and took one quarter of it. It is devoted to present his 'positive' views on machine intelligence. We have just seen that it has a historical grounding in his dialogue with Douglas Hartree, which had started in early November 1946. Moreover, a detailed chronology of Turing's concept of machine intelligence shows no reference to any notion of (machine) 'learning' by Turing prior to early November $1946,{ }^{47}$ when he was interviewed by 
the The Daily Telegraph side by side with Hartree. He had been talking about machine intelligence in general (with no mention of learning) at least since December 1945 . $^{48}$ The historical record thus suggests that Hartree's point (essentially the Lovelace-Hartree thesis) was influent on the formation of Turing's concept of machine intelligence in terms of learning from experience.

\section{Turing provoked by Michael Polanyi}

Michael Polanyi (1913-1976), born Hungarian, left Nazi Germany to England to become F.R.S. in 1944. ${ }^{49}$ In 1948, associated with the Department of Philosophy and with some support from Professor of Philosophy Dorothy Emmet, he was granted a new chair of Social Studies at the University of Manchester. Emmet was an Alfred Whitehead scholar. ${ }^{50}$ Emmet and Polanyi were interested in the postwar public discussion about science and society, and payed attention to the debate around the new computing machines or 'electronic brains.' So they invited Turing, Newman, Jefferson and others to a seminar on 'the mind and the computing machine,' to be held on 27 October 1949 at the Philosophy Department. This would be indeed a crucial event. We know of it mostly from minute notes that survived. ${ }^{51}$ I will cover what I take to have been Polanyi's key interventions that challenged Turing.

The seminar had two sessions. The first session was led by Polanyi, who read a text, entitled 'Can the mind be represented by a machine? Notes for discussion on 27th October 1949,' which he had prepared and circulated to Newman and Turing several weeks before the meeting. ${ }^{52}$ Essentially, Polanyi claimed that humans can solve problems that machines cannot. He vindicated support from Gödel's incompleteness theorems. In what survived of the first session of the seminar, we read:

NEWMAN TO POLANYI: The Gödel extra-system instances are produced according to a definite rule, and so can be produced by a machine. The mind/machine problem cannot be solved logically; it must rest on a belief that a machine cannot do anything radically new, to be worked on experimentally. The interesting thing to ask is whether a machine could produce the original Gödel paper, which seems to require an original set of syntheses.

TURING: emphasises the importance of the universal machine, capable of turning itself into any other machine.

POLANYI: emphasises the Semantic Function, as outside the formalisable system. ${ }^{53}$

This suggests that Newman considered, like Turing, that 'the mind/machine problem' can be decided empirically and only empirically. Moreover, Newman shifted the discussion around Polanyi's Gödelian argument to the Lovelace-Hartree thesis. So Turing and Newman seem to have tried to extract some philosophical substance from Polanyi's point. Specifically, Newman had cast the problem of 'produc[ing] the original Gödel paper' as an instance of Lady Lovelace's objection, that is, the question whether a machine can 'do anything radically new'. Indeed, this had been suggested by Turing himself ever since his February 1947 lecture on the ACE, when he connected his response to (then yet unnamed) Lady Lovelace's objection ${ }^{54}$ with his response to Gödel's argument or the mathematical objection $^{55}$ through the concept of machine learning.

Polanyi's appeal to a 'Semantic Function' would be extended into the second session of the seminar, chaired by Dorothy Emmet, and lead to new exchanges with Turing. At some point, we see that Turing would have presented a distinction, to which Polanyi replied:

TURING: declares he will try to get back to the point: he was thinking of the kind of machine which takes problems as objectives, and the rules by which it deals with the problems are different from the objective. Cf. Polanyi's distinction between mechanically following rules about which you know nothing, and rules about which you know.

POLANYI: tries to identify rules of the logical system with the rules which determine our own behaviour, 
and these are quite different things. ${ }^{56}$

Here lies the motivation for Turing's 1950 formulation and rebuttal of 'the argument from informality of behaviour'. ${ }^{57}$ Now, writing nine years after the October 1949 seminar in Manchester, Polanyi gave this even more valuable piece of historical information:

A. M. Turing has shown [Polanyi's note: in a communication to a Symposium held on "Mind and Machine" at Manchester University in October, 1949. This is foreshadowed in 'Systems of Logic based on Ordinals', Proc. London Maths. Soc., Series 2, 45, 1938-9, pp. 161-228.] that it is possible to devise a machine which will both construct and assert as new axioms an indefinite sequence of Gödelian sentences. Any heuristic process of a routine character - for which in the deductive sciences the Gödelian process is an example could likewise be carried out automatically. A routine game of chess can be played automatically by a machine, and indeed, all arts can be performed automatically to the extent to which the rules of the art can be specified. ${ }^{58}$

Polanyi thus sourced a key historical fact, namely, as of late October 1949 Turing was still referring to the game of chess as intellectual task to illustrate and test for machine intelligence. But as we combine what Polanyi is reported to have said the notes of the 1949 seminar with what he wrote years later in 1958 (see both quotations above), we observe that Polanyi himself replied to Turing by classing chess as an art that 'can be performed automatically' because its rules 'can be specified.' So in October 1949 Turing had seen his reference to machine chess to sound unimpressive to philosophers.

It turns out that in his 'Intelligent machinery' report written in the summer of 1948 Turing had discussed a tradeoff between most convenient and most impressive intellectual fields:

Of the above possible fields [including "various games e.g. chess"] the learning of languages would be the most impressive, since it is the most human of these activities. This field seems however to depend rather too much on sense organs and locomotion to be feasible. ${ }^{59}$

And indeed Turing presented at the end of his 1948 report an imitation test for machine intelligence based on the game of chess. So after considering strenghts and weaknesses of various intellectual tasks and fields to illustrate, develop and test for machine intelligence, he chose chess-playing. Indeed, this choice of his comes from as early as his wartime service in $1941^{60}$ and went through late $1945 .{ }^{61}$ Furthermore, it was kept as of his February 1947 lecture $^{62}$ and through his summer 1948 report, at least until the Manchester seminar in October 1949 as related by Polanyi. But as of writing his seminal paper in early 1950, Turing would have second thoughts and replace chess, his well-established task, to conversational question-answering or a viva-voce test (within the field of the learning of languages). We can now revisit the question: why did he make this move?

My suggested answer runs as follows. As we have seen from his exchanges with Polanyi, he noticed that chess-playing would not suit to his goal, which according to Robin Gandy was to persuade 'philosophers and mathematicians and scientists to take seriously the fact that computers were not merely calculating engines but were capable of behaviour which must be accounted as intelligent'.

At the end of his 1950 paper Turing reconsidered it:

We may hope that machines will eventually compete with men in all purely intellectual fields. But which are the best ones to start with? Even this is a difficult decision. Many people think that a very abstract activity, like the playing of chess, would be best. It can also be maintained that it is best to provide the machine with the best sense organs that money can buy, and then teach it to understand and speak English. This process 
could follow the normal teaching of a child. Things would be pointed out and named, etc. Again I do not know what the right answer is, but I think both approaches should be tried. ${ }^{63}$

Indeed, Turing was not quite sure. As he had already suggested in the summer of 1948, he hesitated about the cost of providing 'child machines' with 'sense organs and locomotion' so that they could learn a language. Clearly, chess was more convenient to enable initial experiments at the early 1950's, while conversational question-answering was still an imaginary experiment and yet preferable for persuasion. In further discussions with essentially the same interlocutors, Turing reassured his proposal of various forms of viva-voce examination to test for machine intelligence in $1951,{ }^{64}$ and in $1952 ;{ }^{65}$ and in the turn from 1952 to 1953 he reconsidered the virtues of chess again. ${ }^{66}$

Indeed, Turing never determined one single and special form of (species) test to be a decisive experiment for human-level machine intelligence. He rather acknowledged the existence of several 'imitation tests'. ${ }^{67}$ In short, I suggest, Turing felt compelled to drop the game of chess as his chosen task for illustrating, developing and testing machine intelligence, if for nothing else, after Polanyi's criticism that chess was an art that 'can be performed automatically' because its rules 'can be specified.'

So far we have seen that in his 1950 paper Turing responded to criticisms from Hartree (November 1946 and June 1949), and from Polanyi (October 1949). In particular, we have seen that Turing left chess as sort of a second option to embody an intelligence test after Polanyi's criticism. It turns out that his positive adoption of linguistic performance instead of chess-playing also has historical roots, namely, in his exchanges with Jefferson in the same period (late 1949) as we shall now see. And it was Jefferson who became Turing's primary antagonist indeed.

\section{Turing provoked by Geoffrey Jefferson}

Geoffrey Jefferson (1886-1961), then Professor of Neurosurgery at the University of Manchester and Fellow of the Royal Society since $1947,{ }^{68}$ had read his Lister Oration on 9 June 1949 in London, where he issued criteria and demands to 'agree that machine equals brain'. The text was published two weeks later in the British Medical Journal (BMJ). ${ }^{69}$ Jefferson had entitled his oration 'The mind of mechanical man' in response to Norbert Wiener's 1948 Cybernetics and to the several digital computing projects in the UK and the US, notably the one Turing was engaged in which was hosted at his University of Manchester. A reporter from The Times covered Jefferson's memorial and emphasized one of his strong observations, which was thus quoted the next day (10 June 1949) under headline 'No mind for mechanical man':

$[\mathrm{N}]$ ot until a machine can write a sonnet or a concerto because of thoughts and emotions felt, and not by the chance fall of symbols, could we agree that machine equals brain - that is, not only write it but know that it had written it. No mechanism could feel (and not merely artificially signal, an easy contrivance) pleasure at its successes, grief when its valves fuse, be warmed by flattery, be made miserable by its mistakes, be charmed by sex, be angry or miserable when it cannot get what it wants. ${ }^{70}$

The reporter from The Times looked for the Computing Laboratory at the University of Manchester to get a reply to Jefferson's claims. Once asked, Turing replied sharply, in wit. ${ }^{71}$ On the next day (11 June 1949), he was thus cited in the newspaper under headline 'Calculus to Sonnet:'

Mr. Turing said yesterday: "This is only a foretaste of what is to come, and only the shadow of what is going to be. We have to have some experience with the machine before we really know its capabilities. It may take years before we settle down to the new possibilities, but I do not see why it should not enter any one of the fields normally covered by the human intellect, and eventually compete on equal terms". "I do not think you can even draw the line about sonnets, though the comparison is perhaps a little bit unfair because a sonnet 
written by a machine will be better appreciated by another machine". Mr. Turing added that the University was really interested in the investigation of the possibilities of machines for their own sake. Their research would be directed to finding the degree of intellectual activity of which a machine was capable, and to what extent it could think for itself. News of the experiments was disclosed by Professor Jefferson in the Lister Oration reported in The Times yesterday. ${ }^{72}$

Two weeks later when Jefferson's Lister Oration appeared in the BMJ (25 June), Turing did not escape a warning note from the editorial that opened the edition:

Mr. A. W. Turing [sic], who is one of the mathematicians in charge of the Manchester "mechanical brain," said in an interview with The Times (June 11) that he did not exclude the possibility that a machine might produce a sonnet, though it might require another machine to appreciate it. Probably he did not mean this to be taken too seriously $[\ldots]^{73}$

Turing would push back. It turns out that a sonnet-writing machine is just what he presented in his 1950 paper. This is evidence that not only Polanyi's negative point about chess but also Jefferson's positive demand about sonnets influenced Turing to shift from chess to conversation for testing machine intelligence. Turing quoted Jefferson's demands and addressed Jefferson directly:

I am sure that Professor Jefferson does not wish to adopt the extreme [...] point of view. Probably he would be quite willing to accept the imitation game as a test. The game (with the player B omitted) is frequently used in practice under the name of viva voce to discover whether some one really understands something or has 'learnt it parrot fashion'. ${ }^{74}$

Jefferson's Lister Oration, in fact, had posed a bold critique of the Turing-Wiener analogy between the new electronic computing machines and the human brain. He spoke out against the idea that machines could think and even tied it to 'political' and 'religious' issues. He urged that 'the concept of thinking like machines lends itself to certain political dogmas inimical to man's happiness [and] erodes religious beliefs that have been mainstays of social conduct'. ${ }^{75}$ The influence of Jefferson's text on Turing's 1950 paper is material and enormous. While this general notion shall not be surprising within Turing scholarship, Jefferson's influence on Turing's 1950 paper is yet to be fully appreciated.

Very recent evidence suggests that another edition of the seminar took place in December 1949. Jonathan Swinton located a Christmas Eve postcard sent to cybernetician Warren McCulloch then in Chicago by a Jules Bogue, an industrialist in the chemical sector and neighbor of Max Newman that found his way into the meeting:

I wish you [McCulloch] had been with us a few days ago we had an amusing evening discussion with Thuring [sic], Wiliams [sic], Max Newman, Polanyi, Jefferson, JZ Young \& myself. An electronic analyser and a digital computer (universal type) might have sorted the arguments out a bit. ${ }^{76}$

Some chaos was noted in the arguments during the discussion in December 1949, which may explain Turing's will to propose the imitation game 'as a basis for discussion'. ${ }^{77}$

Now, I have observed that this finding of Swinton's correlates with what Jefferson related in a letter after Turing's death. Jefferson described an event when Turing would have come to his house to talk to Professor J.Z. Young and him over dinner after a meeting in the Philosophy Department. The key information that Jefferson gave was that after midnight Turing went off to ride home on his bicycle 'through the same winter's rain'. ${ }^{78}$ So, if we take Jefferson's word at face value, that meeting cannot have been the seminar held on 27 October 1949 (in the fall), and must have taken place in late 
December (in the winter) near Christmas eve. In effect, given that the minute notes of the October 1949 edition do not show any exchange between Jefferson and Turing, ${ }^{79}$ it must have been in this December meeting (extended into late night at Jefferson's house) that they had their most lively exchanges; and this must have been when Jefferson drew Turing's attention to his Lister Oration.

We know that Turing possessed and annotated an offprint of Jefferson's Lister Oration at the time he was writing his own in January 1950. It has been delivered to the King's College Archive at the University of Cambridge after Turing's death, and the Archive's catalog entry describes it as having 'annotations by AMT (Alan Turing)'. ${ }^{80}$ Darren Abramson drew attention to that in $2011 .{ }^{81} \mathrm{He}$ reports to have located two heavy markings in the offprint, which gives material evidence that Turing read and annotated Jefferson's text. Turing marked in pencil two passages: Jefferson's demands that appeared in The Times as we have seen above, and Jefferson's exposition of René Descartes's 1637 Discourse on method, Part V. ${ }^{82}$ The latter presented the sensible image proposed by Descartes, as known, of a vivavoce examination to distinguish human beings from machines and other animals however good their imitation of human behaviour could look at a first glance. ${ }^{83}$ Towards the end of his oration Jefferson returned to Descartes to suggest speech as the most distinctive intellectual faculty of 'man' as opposed to 'the highest animal', ${ }^{84}$ and further required that thinking machines should be able to write a sonnet 'because of thoughts and emotions felt'. ${ }^{85}$ So by imagining a machine being questioned about a sonnet composed by itself in his 1950 imitation game or test, ${ }^{86}$ Turing addressed Jefferson's demands — say, writing a sonnet and passing a viva-voce test about it - both at once.

Now, there is another move of Jefferson's that to my knowledge has never been observed in the secondary literature and yet is crucial for the intelligibility of Turing's test. It turns out that Jefferson offered a second image to Turing, and this one was no less striking. Jefferson referred to 'sex hormones' as a distinctive feature of the behaviour of 'animals' and 'men,' as opposed to 'modern automata'. ${ }^{87}$ In this connection, he referred to the iconic electromechanical tortoises of Grey Walter:

[...It] should be possible to construct a simple animal such as a tortoise (as Grey Walter ingeniously proposed) that would show by its movements that it disliked bright lights, cold, and damp, and be apparently frightened by loud noises, moving towards or away from such stimuli as its receptors were capable of responding to. In a favourable situation the behaviour of such a toy could appear to be very lifelike - so much so that a good demonstrator might cause the credulous to exclaim "This is indeed a tortoise." I imagine, however, that another tortoise would quickly find it a puzzling companion and a disappointing mate. $^{88}$

Jefferson further remarked that 'neither animals nor men can be explained by studying nervous mechanics in isolation, so complicated are they by endocrines, so coloured is thought by emotion.' He then completed: '[s]ex hormones introduce peculiarities of behaviour often as inexplicable as they are impressive'. ${ }^{89}$ In short, Jefferson suggested that machines could not exhibit enough peculiarities of behaviour to be able to imitate the actions of animals or 'men' because they have no sex hormones. A machine would give itself away and be found to be 'a puzzling companion and a disappointing mate.' Jefferson thus suggested that the physiology of sex hormones is causally related with interesting behaviour, meaning gendered behaviour.

In Jefferson's passage quoted by The Times in June 1949, it is notable his demand that machines should be able to have emotional reactions in general and be capable of being 'charmed by sex' in particular, if they are to be said to think. In his 1950 paper, Turing addressed this in his discussion of objection (5) 'Arguments from various disabilities'. ${ }^{90}$ Among other non-obvious things, he considered to 'fall in love' and 'make someone fall in love with it' as capabilities that do are within the reach of machines. 
Although Turing did not address Jefferson's tortoise challenge directly, one may note that for a machine not to be a puzzling companion and a disappointing mate in the sense of Jefferson, it must be able to learn and imitate gender. But Turing addressed the tortoise challenge more subtly, one may say, in the very design of his imitation game. He modified the viva-voce examination proposed by Descartes in 1637 in a few key aspects. In Descartes's test, there were only two participants: the one contestant entity - say, an animal or machine - and the human interrogator who inquiries it. Turing, having introduced an arrangement for blind communication to control for bias, introduced another arrangement for a third player B supposed "to help the interrogator" in making the right decision. Player B is meant to be gendered and to sit side by side with player A, that is, to serve as a baseline model of its gender performance in the unrestricted conversation conducted by the examiner. Now, let us recall Jefferson's argument about the influence of sex hormones in the production of peculiarities of behavior in "animals" and "men." It turns out that Jefferson offered the image of an electromechanical tortoise that is put side by side with an actual tortoise. Suppose by analogy that we consider, say, as Jefferson suggested in the title of his Lister Oration, a "mechanical man" side by side with an actual woman or man. Turing's question is thus posed: without being able to see, touch or hear the two, would one be able to tell them apart correctly? Or would it, as predicted by Jefferson in his critique of Walter's electromechanical tortoise, be quickly found to be "a puzzling companion and a disappointing mate"? If the thesis that sex hormones are crucial to produce interesting behavior was also at stake, then Descartes's language test by itself, even if fixed by Turing's arrangement for blind communication, would fall short at satisfying one of Jefferson's conditions for machine intelligence. It would have to be extended along the lines of Turing's imitation game. If player A can imitate well the required gender, then it will showcase not only human intelligence in general but also the 'peculiarities of behaviour' that according to Jefferson would be rendered by specific (male and female) 'sex hormones.'

\section{Conclusion}

Turing's 1950 proposal of a test for machine intelligence is still fairly controversial. His seminal paper is often said to be accessible for a general readership and yet to be complex, multi-layered and too ambiguous for scientific and philosophical interpretation if not even contradictory. In this article I have drawn attention to the mind-machine controversy in England, 1946-1950, which led to Turing to propose his famous imitation game or test for machine intelligence. I have provided original answers to key exegetical and historical questions that have not been suitably addressed so far.

Indeed, Turing spent several years - from $c$. 1941 to late 1949 — working with chess-playing as a task to illustrate, develop and test for machine intelligence. At least since his indirect dialogue with Hartree about the cognitive capabilities and limitations of the ACE in late 1946, Turing had been thinking of making a machine to play chess by learning from experience. His goal was to establish a concept of machine intelligence that would not fall prey to the Lovelace-Hartree thesis. Learning from experience was the answer that Turing provided in light of Hartree's criticism, and it could be illustrated quite well in the game of chess. But in October 1949 his argument based on chess received criticism from Polanyi, who was unimpressed and posed that chess was an art that 'can be performed automatically,' for its rules 'can be specified.' Not less importantly, late that year Jefferson drew Turing's attention to his Lister Oration. Jefferson had shed light on Descartes's proposal of a viva-voce examination to distinguish humans from machines and other animals, and pointed out speech as the highest form of human intelligence. Jefferson's emphasis on speech was such that the climax of his Lister Oration was to require that thinking machines should be able to write a sonnet. But he required furthermore that linguistic performance should be tied to emotions. Also in his oration, Jefferson had pointed to Grey Walter's iconic electromechanical tortoises and suggested that machines could not exhibit enough peculiarities of behaviour to be able to imitate the actions of animals or 'men' because they have no sex 
hormones. A machine would give itself away and be found to be 'a puzzling companion and a disappointing mate.' In doing so, Jefferson suggested that the physiology of sex hormones is causally related with gendered behaviour. Turing challenged Jefferson's position through an irreverent adaptation of Descartes's test. I suggest that Turing's dialogue with Jefferson's Lister Oration provides evidence that Turing did propose gender learning and imitation as one of his various historical tests for machine intelligence. ${ }^{91}$

Altogether, I have explained Robin Gandy's anecdote on the purpose of the Turing test, and singled out Turing's most notable interlocutors - the 'philosophers and mathematicians and scientists' that Turing 'sought to persuade' about the cognitive capabilities of digital computers. Turing's direct and indirect discussion with these three thinkers - Hartree, Polanyi and Jefferson —, I hold, is key for any exegesis of Turing's 1950 paper and to an understanding of the conceptual problems he tried to solve in his proposal of the imitation game that became widely known as his test for machine intelligence.

\section{Acknowledgements}

This research has been supported by The São Paulo Research Foundation (FAPESP) under grant number 19/21489-4 'The future of artificial intelligence: the logical structure of Alan Turing's argument'. 
1 Yiannis Moschovakis and Mike Yates, 'In memoriam: Robin Oliver Gandy 1919-1995', The Bulletin of Symbolic Logic, (1996) 2(3), pp. 367-8, doi:10.1017/S1079898600007873.

2 B. Jack Copeland (ed.), The essential Turing, the ideas that gave birth to the computer age, Oxford: Oxford University Press, 2004, p. 433.

3 Robin Gandy, 'Human versus mechanical intelligence', in Peter Millican and Andy Clark (eds.), Machines and thought, the legacy of Alan Turing, Oxford: Oxford University Press, 1996, vol. 1, p. 125.

4 Alan M. Turing, 'Computing machinery and intelligence', Mind, (1950), LIX(236), pp. 433-60. doi:10.1093/mind/LIX.236.433.

5 Daniel Dennett, 'Can machines think?', in Christof Teuscher (ed.), Alan Turing, life and legacy of a great thinker, Berlin: Springer, 2006 [1984], pp. 295-316; reprinted with added 1985 and 1997 postscripts 'Eyes, ears, hands and history' and no title, from M. G. Shafto (ed.), How we know, San Francisco: Harper \& Row, 1984, pp. 121-145; B. Jack Copeland, The Turing test. Minds and Machines, (2000) 10(4), pp. 519-39, doi:10.1023/A:1011285919106; and James Moor, 'The status and future of the Turing test', Minds and Machines, (2001) 11(1), pp. 77-93, doi:10.1023/A:1011218925467.

6 Dennett, op. cit. (5), p. 297.

7 Turing, op. cit. (4), appearing respectively in pp. 433-4, and p. 442.

8 Patrick Hayes and Kenneth Ford, 'Turing test considered harmful', in Proceedings of the 14th International Joint Conference on Artificial Intelligence, 1995, pp. 972-7; Drew McDermott, 'What was Alan Turing's imitation game?', The critique, (2014), part of an issue on Turing's imitation game,

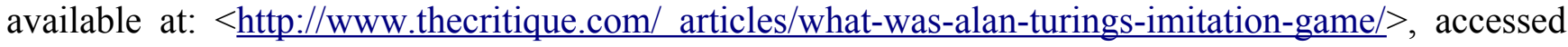
[20 January 2021].

9 Blay Whitby, 'The Turing test: AI's biggest blind alley?' in Peter Millican \& Andy Clark (eds.), Machines and Thought, the legacy of Alan Turing. Oxford: Oxford University Press, 1996, vol. 1; also available at $<$ http://users.sussex.ac.uk/ blayw/tt.html $>$, accessed [3 July 2021].

10 Marvin Minsky, 'Marvin Minsky on AI: the Turing test is a joke!', Interview to the Singularity Weblog, available at: < $\underline{\mathrm{http}}$ ://www.singularityweblog.com/marvin-minsky/>; cf. from 23'35" to 24'45"; accessed [3 July 2021].

11 Noam Chomsky, 'Language and nature' Mind, (1995) 104(413), p. 9, doi:10.1093/mind/104.413.1.

12 G. Oppy and D. Dowe, 'The Turing test', Stanford Encyclopedia of Philosophy, available at: $<$ http://plato.stanford.edu/entries/turing-test/>, first published 9 April 2003, substantive revision 18 August 2020, accessed [3 July 2021].

13 A.P. Saygin, I. Cicekli, and V. Akman, 'Turing test: 50 years later', Minds and Machines, (2000) 10(4), 463-518. doi:10.1023/A:1011288000451.

14 Douglas R. Hartree, Calculating instruments and machines. Urbana: University of Illinois Press, 1949.

15 Geoffrey Jefferson, 'The mind of mechanical man', British Medical Journal, (1949) 1(4616), pp. 1105-10, doi:10.1136/bmj.1.4616.1105.

16 'No mind for mechanical man', The London Times, (10 June 1949), p. 2.

17 'Calculus to sonnet', The London Times, (11 June 1949), p. 4.

18 Alan M. Turing et al., 'Rough draft of the discussion on the mind and the computing machine, held on Thursday, 27th October, 1949, in the Philosophy Seminar', The Rutherford Journal, (2005) 1

(December). Transcript of notes taken during the philosophy seminar co-chaired by Michael Polanyi and Dorothy Emmet at the University of Manchester on 27 October 1949, made available by Wolfe Mays; available at $<$ http://rutherfordjournal.org/article010111.html $>$, facsimile at:

$<$ www.alanturing.net/philosophy_seminar_oct1949/>, accessed [3 July 2021].

19 Cf. Turing, op. cit. (4), p. 450; and Alan M. Turing, 'Can digital computers think?' in B. Jack Copeland (ed.), The essential Turing, the ideas that gave birth to the computer age, Oxford: Oxford University Press, 2004 [15 May 1951], pp. 482-6, p. 485. 
20 Andrew Hodges, 'Alan Turing and the Turing test', in R. Epstein, G. Roberts, and G. Beber (eds.), Parsing the Turing test, philosophical and methodological issues in the quest for the thinking computer, Berlin: Springer, 2009, Chapter 2, pp. 13-22, p. 13, no source is given.

21 Andrew Hodges, Alan Turing: the enigma, the centenary edition, Princeton: Princeton University Press, 2012 [1983].

22 Hodges, op. cit. (21), p. 415.

23 Jonathan Swinton, Alan Turing's Manchester, Manchester: Infang Publishing, 2019.

24 Swinton, op. cit. (23), p. 93, no source is given.

25 Diane Proudfoot, 'Rethinking Turing's test' The Journal of Philosophy, (2013) 110(7), 391- 411.

26 Alan M. Turing, 'Intelligent machinery', in B. Jack Copeland (ed.), The essential Turing, the ideas that gave birth to the computer age, Oxford: Oxford University Press, chapter 10, pp. 410-32, p. 411; facsimile at $<$ http://www.turingarchive. org/browse.php/C/11 $>$, accessed [3 July 2021].

27 Copeland, op. cit. (5).

28 Darren Abramson, 'Descartes' influence on Turing', Studies in History and Philosophy of Science: Part A, (2011) 42(4), 544-51. doi:10.1016/j.shpsa.2011.09.004.

29 Omitted for double-blind review.

30 Charles C. Darwin, 'Douglas Rayner Hartree, 1897-1958', Biographical memoirs of fellows of the Royal Society, (1958) 4 (Nov.), pp. 102-16. doi:10.1098/rsbm.1958.0010.

31 Hartree, op. cit. (14).

32 Hartree, op. cit. (14), p. v; the preface dates to May 1949.

33 Crispin Rope, 'Pioneer profiles: Douglas Hartree', Computer Resurrection, (2010) 49,

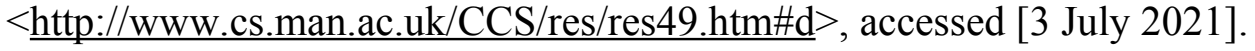

34 Turing, op. cit. (19).

35 Hartree, op. cit. (14), p. 70.

36 Hartree, op. cit. (14), p. 70.

37 Turing, op. cit. (4), pp. 450, 454, 459.

38 Alan M. Turing to Ross Ashby, c. November 1946, W. Ross Ashby Digital Archive; also at

Woodger Papers (catalogue reference M11/99); facsimile available at:

$<$ http://www.rossashby.info/letters/turing.html $>$, accessed [3 July 2021].

39 John R. Womersley, 'A.C.E. Project - Origin and Early History', National Physical Laboratory, 26

November 1946, Public Record Office, Kew, Richmond, Surrey (document reference DSIR 10/385); a digital facsimile is in The Turing Archive for the History of Computing

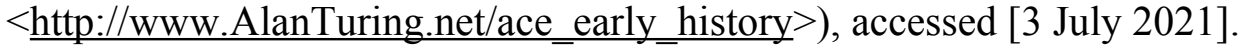

40 Crispin Rope, op. cit. (33).

41 "'ACE" will speed jet flying', The Daily Telegraph, 7 November 1946.

42 Alan M. Turing, 'Lecture on the Automatic Computing Engine', in B. J. Copeland (ed.), The essential Turing, the ideas that gave birth to the computer age, Oxford: Oxford University Press, 2004 [February 1947], pp. 378-94, pp. 392-3.

43 Turing, op. cit. (42), pp. 392-3.

44 Turing, op. cit. (42), p. 393.

45 Norbert Wiener, Cybernetics, or control and communication in the animal and the machine, second edition, Cambridge, MA: MIT Press, 1965 [1948].

46 Wiener, op. cit. (45), pp. 125-6.

47 See 'APPENDIX A - Machine intelligence in Turing's thought (1936-1952)', in Bernardo Gonçalves, Machines will think, structure and interpretation of Alan Turing's imitation game, Doctoral Thesis, Faculdade de Filosofia, Letras e Ciências Humanas, University of São Paulo, São Paulo doi:10.11606/T.8.2021.tde-10062021-173217.

48 See Turing's formulation of problem 10 where he asked the question, 'Can the machine play chess?, in his December 1945 technical report to the National Physical Laboratory. Alan M. Turing, 'Proposed 
electronic calculator', in B. Jack Copeland (ed.), Alan Turing's Automatic Computing Engine, the master codebreaker's struggle to build the modern computer, Oxford: Oxford University Press, 2004 [December 1945], chapter 20, pp. 369-454, p. 389, doi:10.1093/acprof:0so/9780198565932.003.0021; facsimile available at <http://www.alanturing.net/proposed electronic calculator/>, accessed [3 July 2021].

49 E.P. Wigner and R.A. Hodgkin, 'Michael Polanyi, 12 march 1891- 22 february 1976'. Biographical memoirs of fellows of the Royal Society, (1977) 23, pp. 412-48, doi:10.1098/rsbm.1977.0016.

50 Swinton, op. cit. (23), pp. 87-90.

51 Turing et al., op. cit. (18).

52 Polanyi scholar Paul Blum found at the Polanyi archive at the University of Chicago a printed copy of that text containing a few critical annotations by hand, which may have been made by Turing indeed. See Paul R. Blum, 'Michael Polanyi: can the mind be represented by a machine? Documents of the discussion in 1949', Polanyiana, (2000), 1(1-2), p.. 35-60, p. 52, available at $<$ www.polanyi.bme.hu/folyoirat/2010-01/2010-1-2-03-Blum.pdf $>$, accessed [3 July 2021].

53 Turing et al., op. cit. (18).

54 Turing, op. cit. (42), pp. 392-3.

55 Turing, op. cit. (42), pp. 393-4.

56 Turing et al., op. cit. (18).

57 Turing, op. cit. (4), p. 452.

58 Michael Polanyi, Personal knowledge: towards a post-critical philosophy. Chicago: University of Chicago Press, second edition, 1974 [1958], p. 261.

59 Alan M. Turing, 'Intelligent machinery', in B. Jack Copeland (ed.), The essential Turing: the ideas that gave birth to the computer age, Oxford: Oxford University Press, 2004 [1948], chapter 10, pp. 410-32, p. 421; facsimile available at: $<$ http://www.turingarchive. org/browse.php/C/11 $>$, accessed [3 July 2021].

60 B. Jack Copeland and D. Prinz, 'Computer chess: the first moments', in B. Jack Copeland et al. (eds.), The Turing Guide, Oxford: Oxford University Press, 2017, chapter 31, pp. 327-46, p. 329.

61 Turing, op. cit. (48).

62 Turing, op. cit. (42), p. 393.

63 Turing, op. cit. (4), p. 460.

64 Turing, op. cit. (19), p. 484.

65 Alan M. Turing, Richard Braithwaite, Geoffrey Jefferson, and Max Newman, 'Can automatic calculating machines be said to think?', in B. Jack Copeland (ed.), The essential Turing, the ideas that gave birth to the computer age, Oxford: Oxford University Press, 2004 [1952], pp. 494-506, p. 495.

66 Alan M. Turing, 'Chess' ['Digital computers applied to games'], in B. Jack Copeland (ed.), The essential Turing: the ideas that gave birth to the computer age, Oxford: Oxford University Press, 2004 [1953], chapter 16, pp. 569-75, p. 569, facsimile at < http://www.turingarchive.org/browse.php/B/7 $>$, accessed [3 July 2021].

67 '...if the machine was being put through one of my imitation tests, it would have to do quite a bit of acting...'. Turing et al., op. cit. (65), p. 503.

68 F.M.R. Walshe, 'Geoffrey Jefferson, 1886-1961', Biographical memoirs of fellows of the Royal Society, (1961) 7(November), pp. 127-35, doi:10.1098/rsbm.1961.0010.

69 Jefferson, op. cit. (15), p. 1110.

70 The London Times, op. cit. (16); and Jefferson, op. cit. (15), p. 1110.

71 Cf. Lyn Irvine to Antoinette Esher, 24 June 1949; letter by Lyn Irvine, wife of the Computing Laboratory director Max Newman, quoted from by their son in William Newman, 'Alan Turing remembered: a unique firsthand account of formative experiences with Alan Turing', Communications of the ACM, (2012), 55 (12), pp. 39-40, doi:10.1145/2380656.2380682.

72 The London Times, op. cit. (17). 
73 Editorial, 'Mind, machine, and man', British Medical Journal, (1949) 1(4616), 1129-30.

74 Turing, op. cit. (4), p. 446.

75 Jefferson, op. cit. (15), p. 1107.

76 Jules Yule Bogue to Warren McCulloch, c. December 1949, Christmas greetings letter found and transcribed by Jonathan Swinton; original in Warren McCulloch archive, MIT American Philosophical Society; facsimile at $<$ http://www.manturing.net/manufacturing-blog/2019/6/3/manchester-minds-andmit-ones $>$, accessed [3 July 2021].

77 Turing, op. cit. (4), p. 445.

78 Lyn Irvine, 'Foreword to the first edition' in Sara Turing (ed.), Alan M. Turing: centenary edition, Cambridge: Cambridge University Press, 2012 [1959], p. xx.

79 Cf. Turing et al., op. cit. (18).

80 Entry AMT/B/44 of the King's College Archive catalog.

81 Abramson, op. cit. (28), p. 548.

82 Jefferson, op. cit. (15), p. 1106.

83 René Descartes, 'Discourse and essays', in John Cottingham, R. Stoothoff, and D. Murdoch (eds.), The philosophical writings of Descartes, Cambridge: Cambridge University Press, 1985 [1637], vol. I, pp. 111-51.

84 Jefferson, op. cit. (15), p. 1109.

85 Jefferson, op. cit. (15), p. 1110.

86 Turing, op. cit. (4), p. 446.

87 Jefferson, op. cit. (15), p. 1107.

88 Jefferson, op. cit. (15), p. 1107.

89 Jefferson, op. cit. (15), p. 1107.

90 Turing, op. cit. (4), p. 447.

91 As mentioned, Turing made explicit reference to '[his] imitation tests'. See Turing, op. cit. (67). 